\title{
Changes in Nutrition Impact Symptoms, Nutritional and Functional Status during Head and Neck Cancer Treatment
}

\author{
May Kay Neoh ${ }^{1,2}$, Zalina Abu Zaid ${ }^{1, *}$, Zulfitri Azuan Mat Daud ${ }^{1}{ }^{\mathbb{D}}$, Nor Baizura Md. Yusop ${ }^{1} \mathbb{1}$, \\ Zuriati Ibrahim 1(D), Zuwariah Abdul Rahman ${ }^{2}$ and Norshariza Jamhuri 1,2 \\ 1 Department of Nutrition and Dietetics, Faculty of Medicine and Health Sciences, Universiti Putra Malaysia, \\ Seri Kembangan 43400, Selangor, Malaysia; dtneoh@nci.gov.my (M.K.N.); zulfitri@upm.edu.my (Z.A.M.D.); \\ norbaizura@upm.edu.my (N.B.M.Y.); zuriatiib@upm.edu.my (Z.I.); dtshariza@nci.gov.my (N.J.) \\ 2 Department of Dietetic and Food Service, National Cancer Institute, Ministry of Health, 4, Jalan P7, Presint 7, \\ Putrajaya 62250, Malaysia; dtzuwariah@nci.gov.my \\ * Correspondence: zalina@upm.edu.my; Tel.: +603-9769-2961
}

Received: 11 February 2020; Accepted: 26 March 2020; Published: 26 April 2020

\begin{abstract}
Background: The purpose of this study is to evaluate changes in nutrition impact symptoms (NIS) and nutritional and functional status that occur throughout radiotherapy in head and neck cancer (HNC) patients. Methods: A prospective observational study of HNC inpatients who underwent radiotherapy with or without chemotherapy were recruited to participate. Fifty patients were followed for the periods before, in the middle and at the end of radiotherapy. Nutritional parameters were collected throughout radiotherapy. Results: According to Patient-Generated Subjective Global Assessment (PG-SGA), there was an increase from a baseline of $56 \%$ malnourished HNC patients to $100 \%$ malnourished with mean weight loss of $4.53 \pm 0.41 \mathrm{~kg}(7.39 \%)$ at the end of radiotherapy. Nutritional parameters such as muscle mass, fat mass, body mass index, dietary energy and protein intake decrease significantly $(p<0.0001)$ while NIS score, energy and protein intake from oral nutritional supplements (ONS) increased significantly $(p<0.0001)$. Hand grip strength did not differ significantly. All HNC patients experienced taste changes and dry mouth that required ONS at the end of treatment. ONS compliance affected the percentage of weight loss $(p=0.013)$. Conclusions: The intensive nutritional care time point was the middle of RT. The PG-SGA and NIS checklist are useful for monitoring nutrition for HNC patients.
\end{abstract}

Keywords: head and neck cancer; nutritional status; malnutrition; nutrition impact symptoms; dietary intake; oral nutritional supplements

\section{Introduction}

Head and neck cancer (HNC) involves malignancies of the oral and nasal cavities, sinuses, salivary glands, pharynx, larynx, and lymph nodes in the neck. It is the sixth most frequently observed type of cancer worldwide [1]. HNC patients are often malnourished at the time of diagnosis. Prior to the beginning of treatment and during treatment, this is due to the catabolic state induced by the tumor and the side effects from treatment, respectively. Unintentional weight loss is common in HNC, mainly because of the tumor location and related symptoms that interfere with dietary intake. The prevalence of malnutrition in HNC patients at diagnosis ranges from $42 \%$ to $77 \%$ and worsen throughout the treatment [2,3], with rises up to $88 \%$ [4].

The current treatment of advanced HNC requires multimodal therapy. Surgery, radiotherapy (RT), concurrent chemotherapy and radiotherapy (CCRT) have become standards of care for HNC patients. Treatment has improved tumor control $[5,6]$ but brings about various side effects. The common side 
effects of RT with or without chemotherapy in HNC patients are mucositis, dysphagia, xerostomia, altered taste and smell, and chewing and swallowing difficulty [4,7]. These nutrition impact symptoms (NIS) induce pain and an inflammatory response, which limits energy intake and increases the stress response, resulting in weight loss [8] during treatment.

Weight loss among HNC patients during treatment is clinically relevant as it contributes to ineffective treatment responses and an impaired functional performance status, leading to a reduced quality of life and a significantly lower survival rate $[5,6,9]$. Critical weight loss is defined when body weight loss is $>5 \%$ [10]. Langius et al. (2013) found out that patients who experience weight loss $>5 \%$ during RT are independently associated with a 1.7 times higher risk of dying from HNC [10]. The cut-off points for critical weight loss during RT were based on the international consensus statement of the Academy of Nutrition and Dietetics and the American Society for Parenteral and Enteral Nutrition [11]. A HNC patient should be weighed routinely, since any weight loss $>5 \%$ (compared to their usual weight or healthy weight over six months) is a factor contributing to a poor prognosis [12].

The duration of RT for HNC patients is typically set around six to seven weeks and the dosage of RT is determined by the oncologist. This period is the critical period for nutrition assessment, intervention, and monitoring due to rapid changes of NIS and dietary intake. In the HNC population, symptom assessment is often adopted in an effort to restore dietary intake and reduce unintentional weight loss, especially during treatment [13]. Patients will develop NIS at the beginning or middle of their treatment that requires different intensities of nutrition intervention. The European Society for Clinical Nutrition and Metabolism (ESPEN) recommends special attention to RT for HNC, where an adequate nutritional intake should be ensured primarily by individualized nutritional counselling and/or with use of oral nutritional supplements (ONS), in order to avoid nutritional deterioration [14]. The majority of HNC patients receiving RT are recommended for ONS as it has been shown that fat mass and fat free mass remain unaltered in compliant patients during treatment [12], but the timing for initiation has yet to be identified.

Due to the lack of studies that have investigated the progression of NIS, nutrition status, and energy intake from ONS throughout RT treatment, it is harder to identify patients in need of intensive nutritional intervention. Many of the studies have emphasized weight loss and energy intake for the pre-treatment and post-treatment periods, mainly focusing on the effect of treatment $[13,15]$. However, more knowledge is required to study the pattern of changes of diet, ONS energy and protein intake, and risk factors for critical weight loss during RT treatment.

This prospective observational study in HNC patients who were treated with standard treatment allows us to determine changes in NIS and nutritional and functional status among HNC patients during RT. Therefore, this study aims to determine the prevalence and magnitude of weight changes in HNC patients and the relationship with the changes of NIS and nutritional and functional status during RT treatment.

\section{Materials and Methods}

\subsection{Study Design and Setting}

This prospective observational study was conducted among adult HNC in patients who received RT or CCRT from March until December in 2018 at the National Cancer Institute (NCI), Putrajaya, Malaysia. This study used a consecutive technique to recruit every HNC patient who was admitted to receive RT or CCRT at NCI, Putrajaya, based on the inclusion criteria and their informed consent. The RT patients received a RT dosage between 60 to $70 \mathrm{~Gy}$ in daily factions of $2.0 \mathrm{~Gy}$ within 7 weeks, while CCRT patients received additional weekly cisplatin or carboplatin during the 7 weeks of RT. The inclusion criteria were HNC patients who were admitted to a ward having RT within 7 weeks with or without chemotherapy for curative treatment intentions and being aged 18 years or older. Participants were on a $100 \%$ oral intake at the time of the study, and no patient used any form of enteral tube feeding or total parenteral nutrition. Patients were excluded from this study if they were 
involved in another research project and ongoing artificial nutrition (enteral/parenteral) before RT or CCRT. There were three measurement points in this study to assess NIS, and nutritional status and functional status, included at the baseline (week 1), middle (week 4) and end of the RT (week 7).

\subsection{Measures}

\subsubsection{Socioeconomic-Demographic and Clinical Characteristics}

The socioeconomic data included the age, gender, and ethnicity of patients. For the clinical characteristics including co-morbidities, tumor location and stage, type of treatment, and duration and dosage of RT, these were obtained from the computerized hospital information system (HIS).

\subsubsection{Nutritional Status}

\section{Malnutrition Status}

The malnutrition statuses of patients were determined using the scored Patient-Generated Subjective Global Assessment (PG-SGA). The PG-SGA is a global rating and scoring nutritional assessment tool that is specialized for cancer patients [16]. Patients are subjectively categorized as well-nourished (PG-SGA category A), moderately or suspected of being malnourished (PGSGA category B) or severely malnourished (PG-SGA category C) upon completion of the assessment. The scored PG-SGA is a further development of the subjective global assessment (SGA) concept that incorporates a numerical score. A high score indicates a lower nutritional status that requires nutrition intervention. Scores with 0 to 1 point require no intervention, health education for 2 to 3 points, dietetic intervention for 4 to 8 points, and nutrition support for $>9$ points.

Anthropometric Measurements

The anthropometric measurements used in this study include body weight, height, and body composition. Body height was measured using a stadiometer (Seca 222, Medical Scales \& Measuring Systems Seca, United Kingdom). Measurements of body weight and body composition were assessed with a calibrated Tanita total body composition analyzer (model SC 300) which can provide body weight in $\mathrm{kg}$ (up to $0.1 \mathrm{~kg}$ ), fat percentage (up to $0.1 \%$ ), and total muscle mass (up to $0.1 \mathrm{~kg}$ ). The subjects were required to be bare foot and stand upright and front facing during measurement. The subjects were requested to have minimal clothing, empty pockets, and stand upright while barefoot on the metal plate of the scale.

Body mass index (BMI) was calculated as the actual body weight $/$ height ${ }^{2}$ in $\left(\mathrm{kg} / \mathrm{m}^{2}\right)$. BMI was then classified as either underweight (BMI $<18.5 \mathrm{~kg} / \mathrm{m}^{2}$ ), normal (BMI 18.5-24.9 kg/m²), overweight (BMI $\left.25-29.5 \mathrm{~kg} / \mathrm{m}^{2}\right)$ or obese $\left(\mathrm{BMI}>30.5 \mathrm{~kg} / \mathrm{m}^{2}\right.$ ) [17]. Percentage weight loss was calculated as (normal body weight - actual body weight)/(normal body weight) $\times 100$. Normal body weight was defined as the body weight 1 month before treatment and was retrieved from medical records. Actual body weight was assessed at the beginning of treatment.

Dietary Intake and Oral Nutritional Supplements (ONS) Intake

Dietary intake was measured through a $24 \mathrm{~h}$ dietary recall. Food and beverages consumed in the last $24 \mathrm{~h}$, starting from the last midnight and finishing at midnight, were identified by the $24 \mathrm{~h}$ dietary recall. The household serving intake, and subsequently the gram intake of food, was collected for every meal to estimate energy and macronutrient intake. Household portion sizes were used to calculate the grams of food that were consumed. For this purpose, household cups and spoons were applied. The intake of energy and macronutrients was determined.

The Nutritionist Pro software was used to analyze information about the macronutrient intake amount (in grams) and total energy intake (kcal) by entering meal recipes with the exact gram intake of all food items. The software calculates the nutrition facts of the whole foods taken in a day from recall. Data on the total energy and protein intake were recorded to compare with the energy requirements of patients. Total energy and protein intake included energy and protein from the diet and ONS, 
while dietary intake and protein intake included energy and protein contributed from diet alone. ONS energy and protein intake was evaluated from ONS intake during treatment.

Nutrition counselling was given to all patients at diagnosis. An oncology dietitian adapted their diet to improve their nutritional intake, especially emphasizing protein intake and the fractionation of intakes throughout the day. Only when nutritional requirements were not met with dietetic intervention was nutritional supplementation then prescribed according to individual needs.

The number of nutrition supplements cans consumed by each subject was recorded as one of the methods to measure the compliance to nutrition support. Weekly ONS compliance was assessed through intake of the ONS, starting from week 2 after dietary intervention. There was a total of 6 (week 2 until end of treatment) compliance measurements throughout treatment. If the patient consumed $\geq 75 \%$ of the recommended ONS energy and protein, he/she was considered as a "compliant patient" while those who consumed $<75 \%$ of the recommended ONS energy and protein were considered to be "noncompliant patients" [12].

Total energy and protein intake were compared to the energy and protein requirements of patients. According to the Medical Nutrition Therapy Guidelines for Cancer in Adults, Ministry of Health (MOH) [18] and ESPEN 2017 guidelines, the recommended energy and protein requirements for hyper-catabolic patients are 30-35 kcal $/ \mathrm{kg}$ of body weight and $1.2-1.6 \mathrm{~g} / \mathrm{kg}$ of protein [14]. Hyper-catabolism is defined as any cancer patient undergoing treatment here. Energy requirements and protein requirements are based on the actual body weight, unless the patient was overweight (BMI of $>25 \mathrm{~kg} / \mathrm{m}^{2}$ ), where the adjusted body weight was used instead in that case. The adjusted body weight was calculated using the following equation: Adjusted body weight $=$ (Ideal body weight (IBW) $+(($ actual body weight $-I B W) \times 25 \%)$, whereby IBW is the patient's corresponding weight at a BMI of $25 \mathrm{~kg} / \mathrm{m}^{2}$ [19].

\subsubsection{Nutrition Impact Symptoms (NIS)}

The NIS were measured with the Head and Neck Symptoms Checklist ${ }^{\odot}\left(\mathrm{HNSC}^{\odot}\right)$. This instrument aids in the early identification of symptoms that place HNC patients at risk of reductions in dietary intake, weight, and functional performance. This checklist includes 12 of the symptoms included on the PG-SGA (including pain, dry mouth, loss of appetite, constipation, feeling full, diarrhea, sore mouth, nausea, altered smell, vomiting, difficulty swallowing, and taste changes) plus five additional symptoms (lack of energy, depression, difficulty chewing, thick saliva, and anxiety) not included on the PG-SGA but reported in the literature as being associated with reduced dietary intake $[13,20]$. The HNSC ${ }^{\odot}$ also provides space for patients to record any additional NIS interfering with eating. Patients were asked to rate the severity of each symptom and the degree to which it interfered with eating (dietary intake) using a five-point Likert scale ranging from "1, not at all" to "5, a lot" [13]. All 17 symptom scores in the checklist were added together to make a total symptom score which varies from 17 (no symptoms) to 85 (highest score of 5 for every symptom in the list) [8]. If acute symptoms scores were missing for only one week for a particular subject, the scores from the previous week were used [21].

\subsubsection{Functional Status}

Functional status was measured by handgrip strength. The non-dominant hand was measured by using a Jamar hand dynamometer (Fred Sammons Inc, Burr Ridge, IL, USA).

\subsection{Power Calculation}

Minimum sample sizes were calculated as required for a paired t-test using the formula $n=\sigma^{2}\left(Z_{1}\right.$ $\left.-\propto / 2+Z_{1}-\beta\right)^{2} /\left(\mu_{1}-\mu_{2}\right)^{2}$ [22], where $n$ is the number of patients, $Z$ is the level of confidence, $\alpha$ is alpha (0.05), $\beta$ is beta (0.2), $\mu_{1}$ is mean in time 1 and $\mu_{2}$ is mean in time 2 , using body weights previously published by another study [13]. Hence, a minimum sample size of 32 samples is required to be able to reject the null hypothesis with a probability (power) of 0.8 . The type I error probability associated with 
this test of this null hypothesis is 0.05 . With an additional of $20 \%$ dropout rate, the required sample size is 40 samples.

\subsection{Ethical Approval}

This study was registered with The National Medical Research Registry (NMRR ID 17-2647-37667). Ethical approval for the study was obtained from the Medical Research Ethics Committee of the Faculty of Medicine \& Health Sciences, Universiti Putra Malaysia and the Medical Research Ethics Committee (MREC), Ministry of Health Malaysia. Permission to conduct the study was obtained from the director at the NCI, Putrajaya, Malaysia.

\subsection{Statistical Analysis}

All statistical analyses were performed using the Statistical Package for the Social Sciences (SPSS) for Windows, version 23 (SPSS Inc, Chicago, IL, USA). Data were checked for normality via the Shapiro-Wilk test. All data were normally distributed as indicated by $p>0.05$ unless otherwise stated. If the data were not normally distributed, analyses were carried out on natural logarithm of the values to improve the symmetry and homoscedasticity of the distribution.

The descriptive statistics here include percentages, means and standard deviations, used to describe the demographic data, clinical characteristics, nutritional status, anthropometric data, biochemical data, nutrition impact symptoms, and dietary intake. The values from different groups were compared by using an independent t-test. For non-normally distributed or ordinal data, the Mann-Whitney U-test was carried out to test the differences between groups and Spearman's rho test was used to evaluate the association between two numerical variables. A chi-square test was used to see the significant differences between groups for categorical data. Changes of fat mass, total energy and protein intake, dietary energy and protein intake, ONS energy and protein intake over time were analyzed by the Friedman test.

Body weight, muscle mass, NIS score and handgrip strength are expressed as the mean \pm SD, and changes over time were analyzed by the general linear model with repeated measures. In the case of deviation from sphericity, a Greenhouse Geisser correction for degrees of freedom was used. The relationship of continuous data were analyzed with Pearson's correlation, while categorical data was analyzed with Spearman test. For the purpose of this analysis, patients were classified as either well-nourished (PG-SGA A) or malnourished (PG-SGA B and C). A statistical probability of $p<0.05$ was considered as significant.

\section{Results}

\subsection{Baseline Characteristics}

Fifty-four patients consented to participate (see Figure 1) for this study. A total of four patients were excluded with two patients who did not meet the study's criteria and another two who did not complete treatment. Fifty subjects were able to complete RT treatment as inpatients and be followed up for data collection until the end of treatment.

Body composition measurements were performed with 49 patients, as there was an error with a patient's data during the Tanita bioelectrical impedance analysis due to a low-fat percentage with an underweight condition. In all other measurements, the data of 50 patients were used in the analysis.

The study results show that there were more male than female patients with $\mathrm{HNC}$ (78\% versus $22 \%$ ) and the mean age of the population was 57 years (SD of two) with a range of 21-78 years old. There were twenty-one (42\%) Malay, nineteen (38\%) Chinese, and ten (20\%) Indian patients, respectively. More than half of the HNC (52\%) subjects in this study had nasopharynx cancer and $84 \%$ were in an advanced stage of the tumor. In addition, thirty-three $(60 \%)$ received CCRT while seventeen $(34 \%)$ received RT only. All subjects received a total of $60 \mathrm{~Gy}$ and above 30 fractions of radiation dosage (Table 1). 


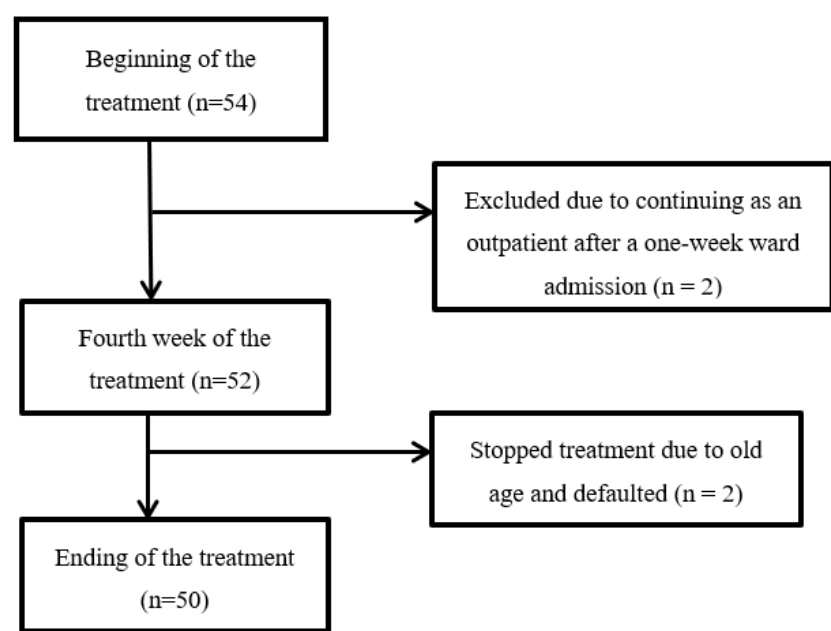

Figure 1. Flow diagram of the protocol.

Table 1. Baseline patient characteristics.

\begin{tabular}{|c|c|c|c|c|}
\hline Characteristics & Overall $(n=50)$ & $\begin{array}{l}\text { Well nourished } \\
\quad(n=22)\end{array}$ & $\begin{array}{l}\text { Malnourished } \\
\quad(n=28)\end{array}$ & $p$-Value \\
\hline $\begin{array}{c}\text { Age }\left(\text { years) }{ }^{\mathrm{b}}, \text { median }\right. \\
(\mathrm{IQR})\end{array}$ & $60(49-67)$ & $54(44-67)$ & $61(52-66)$ & 0.163 \\
\hline $\begin{array}{c}\text { Gender }^{c}: n(\%) \\
\text { Male }\end{array}$ & $\begin{array}{l}39(78) \\
11(22)\end{array}$ & $\begin{array}{l}16(41) \\
6(54.5)\end{array}$ & $\begin{array}{l}23(59) \\
5(455)\end{array}$ & \multirow[t]{2}{*}{0.425} \\
\hline Female & $11(22)$ & $6(54.5)$ & $5(45.5)$ & \\
\hline Race $^{\mathrm{c}}: n(\%)$ & $21(42)$ & $9(42.9)$ & 12 (57.1) & \multirow[t]{3}{*}{0.501} \\
\hline Malay & 19 (38) & $10(52.6)$ & 9 (47.4) & \\
\hline $\begin{array}{l}\text { Chinese } \\
\text { Indian }\end{array}$ & $10(20)$ & $3(30)$ & $7(70)$ & \\
\hline Tumor location: $n(\%)$ & & & & \multirow{9}{*}{ - } \\
\hline Tongue & $7(14)$ & $3(42.9)$ & $4(58.1)$ & \\
\hline Mouth & $6(12)$ & $2(33.3)$ & $4(66.7)$ & \\
\hline Salivary gland & $3(6)$ & $1(33.3)$ & $2(66.7)$ & \\
\hline Tonsil & $2(4)$ & $0(0)$ & $2(100)$ & \\
\hline Oropharynx & $2(2)$ & $0(0)$ & $2(100)$ & \\
\hline Nasopharynx & $26(52)$ & 15 (57.7) & $11(42.3)$ & \\
\hline Sinuses & $1(2)$ & $0(0)$ & $1(100)$ & \\
\hline Larynx & $3(6)$ & $1(33.3)$ & $2(66.7)$ & \\
\hline Stage of tumor ${ }^{d}: \mathbf{n}(\%)$ & $8(16)$ & $5(62.5)$ & $3(37.5)$ & \multirow{2}{*}{0.277} \\
\hline $\begin{array}{l}1-2 \\
3-4\end{array}$ & $42(84)$ & $17(34)$ & $25(50)$ & \\
\hline Type of treatment ${ }^{c}: n(\%)$ & & & & \multirow{3}{*}{0.773} \\
\hline Radiotherapy & $17(34)$ & $7(41.2)$ & $10(58.8)$ & \\
\hline Chemoradiotherapy & $33(66)$ & $15(45.5)$ & $18(54.5)$ & \\
\hline
\end{tabular}

${ }^{b}$ Mann Whitney U-test. ${ }^{c}$ Chi-square test for proportions. ${ }^{d}$ Fisher's exact test.

\subsection{Changes in Nutritional Status, Nutrition Impact Symptoms (NIS) and Functional Status}

\subsubsection{PGSGA}

The pre-treatment prevalence of malnutrition was 56\% (28 of 50). Only one third of the malnourished patients had received dietary intervention before treatment. At the end of treatment, all subjects were malnourished, where 32\% (16) were moderately malnourished and 68\% (34) were severely malnourished (Table 2). There was an increase of severely malnourished HNC patients from $20 \%$ at the baseline to $68 \%$ at the end of treatment. All HNC patients required critical intervention at the end of treatment. At the end of treatment, $68 \%$ HNC patients had $>5 \%$ weight loss with $30 \%$ of them experiencing $>10 \%$ severe weight loss. 
Table 2. Nutritional status, nutrition impact symptoms, ONS compliance, and type of diet at baseline and end of treatment.

\begin{tabular}{|c|c|c|}
\hline Characteristics, $n(\%)$ & Baseline $(n=50)$ & End $(n=50)$ \\
\hline \multicolumn{3}{|l|}{ PG-SGA global rating } \\
\hline A (well-nourished) & $22(44)$ & - \\
\hline B (moderate malnourished) & $18(36)$ & $16(32)$ \\
\hline $\mathrm{C}$ (severe malnourished) & $10(20)$ & $34(68)$ \\
\hline \multicolumn{3}{|l|}{ Triage intervention } \\
\hline No intervention (Score of $0-1$ ) & $4(8)$ & - \\
\hline Health education (Score of 2-3) & $13(26)$ & - \\
\hline Dietetic intervention (Score of $4-8$ ) & $10(20)$ & - \\
\hline Critical interventions $(\geq 9)$ & $23(46)$ & $50(100)$ \\
\hline BMI category & & \\
\hline Underweight $\left(<18.5 \mathrm{~kg} / \mathrm{m}^{2}\right)$ & $12(24)$ & $19(38)$ \\
\hline Normal weight $\left(18.5-24.9 \mathrm{~kg} / \mathrm{m}^{2}\right)$ & $25(50)$ & $21(42)$ \\
\hline Overweight $\left(25-29.9 \mathrm{~kg} / \mathrm{m}^{2}\right)$ & $5(10)$ & $6(12)$ \\
\hline Obese (>30 kg/m²) & $8(16)$ & $4(8)$ \\
\hline \multicolumn{3}{|l|}{ Weight loss: $n(\%)$} \\
\hline None & $\begin{array}{l}14(28) \\
30(60)\end{array}$ & $15(30)$ \\
\hline$<5 \%$ in 1 month & $30(60)$ & $15(30)$ \\
\hline $5-10 \%$ in 1 month & $5(10)$ & $19(38)$ \\
\hline$>10 \%$ & $1(2)$ & $15(30)$ \\
\hline Mean \pm SD & - & $7.39 \pm 4.07$ \\
\hline \multirow{3}{*}{\multicolumn{3}{|c|}{$\begin{array}{c}\text { Nutrition Impact Symptoms (NIS) } \\
\text { Yes } \\
\text { No }\end{array}$}} \\
\hline & & \\
\hline & & \\
\hline ONS compliance & - & $37(74)$ \\
\hline Compliant & - & $13(26)$ \\
\hline \multicolumn{3}{|l|}{ Non-compliant } \\
\hline Type of diet & $36(72)$ & $1(2)$ \\
\hline Normal & $8(16)$ & $20(40)$ \\
\hline Soft & $6(12)$ & 23(46) \\
\hline Liquid diet & - & $6(12)$ \\
\hline Tube feeding & & \\
\hline
\end{tabular}

Abbreviations: PG-SGA: patient-generated subjective global assessment, BMI: body mass index, ONS: oral nutrition supplements.

\subsubsection{Anthropometric Data}

The mean pre-treatment body weight significantly declined from $60.24 \pm 14.73 \mathrm{~kg}$ to $57.95 \pm$ $13.92 \mathrm{~kg}$ at the middle of treatment and further reduced to $55.71 \pm 13.62 \mathrm{~kg}$ at the end of treatment $(p<0.001$; mean decline of $4.53 \pm 2.87 \mathrm{~kg})$. The muscle mass at end of treatment was $41.3 \pm 8.13 \mathrm{~kg}$, which was declined from the baseline of $43.03 \pm 8.12 \mathrm{~kg}(p<0.001$, mean decline of $1.73 \pm 2.17 \mathrm{~kg})$ (Table 3). Repeated measures of analysis of variance showed that marked decreases were noted in anthropometric data which included the mean body weight, muscle mass and fat mass from baseline to mid-treatment and from mid-treatment to post-treatment. At the end of treatment, $42 \%$ of patients had a normal weight, $12 \%$ were overweight, $8 \%$ were obese, followed by increases of being underweight from $24 \%$ at baseline to $38 \%$ at the end of treatment (Table 3). Patients lost $4.53 \pm 0.41 \mathrm{~kg}(95 \% \mathrm{CI}$, 3.72 to $5.35 \mathrm{~kg}$ ) of body weight, which corresponds to an average of $7.39 \%$ body weight loss (Table 2). 
Table 3. Changes in nutritional parameters along the treatment $(n=50)$.

\begin{tabular}{|c|c|c|c|c|c|}
\hline Variables $(n=50)$ & $\begin{array}{c}\text { Baseline } \\
\text { Mean } \pm \text { SD }\end{array}$ & $\begin{array}{c}\text { Middle of RT } \\
\text { Mean } \pm \text { SD }\end{array}$ & $\begin{array}{c}\text { End of RT } \\
\text { Mean } \pm \text { SD }\end{array}$ & $X^{2}$ & $p$-Value \\
\hline Body weight $(\mathrm{kg})^{+}$ & $60.24 \pm 14.73$ & $57.95 \pm 13.92$ & $55.71 \pm 13.62$ & 14.731 & $<0.0001$ * \\
\hline BMI $(\mathrm{kg} / \mathrm{m} 2) \mathbb{I}$ & $22.78 \pm 5.6$ & $21.92 \pm 5.29$ & $21.08 \pm 5.19$ & 81.437 & $<0.0001 *$ \\
\hline PGSGA score $^{a}$ & $8.72 \pm 6.86$ & - & $25.82 \pm 5.34$ & 58.47 & $<0.0001^{*}$ \\
\hline Muscle mass $(\mathrm{kg})^{\dagger}$ & $43.03 \pm 8.12$ & $41.99 \pm 8.28 \mathrm{~kg}$ & $41.30 \pm 8.13$ & 4.286 & $<0.0001 *$ \\
\hline Fat mass $(\mathrm{kg})$ पा & $15.23 \pm 9.17$ & $14.07 \pm 8.43$ & $12.67 \pm 8.3$ & 62.23 & $<0.0001 *$ \\
\hline $\begin{array}{c}\text { Non-dominant hand } \\
\text { handgrip strength }(\mathrm{kg})^{\dagger}\end{array}$ & $25.17 \pm 7.46$ & $25.06 \pm 8.26$ & $24.454 \pm 7.97$ & 5.207 & 0.483 \\
\hline NIS score & $21.78 \pm 4.59$ & $39.68 \pm 9.54$ & $48.34 \pm 8.79$ & 78.707 & $<0.0001$ * \\
\hline $\begin{array}{l}\text { Total Energy Intake } \\
{\text { (Kcal/day })^{+}}^{+}\end{array}$ & $1412 \pm 589$ & $1403 \pm 465$ & $1554 \pm 482$ & 1.241 & 0.227 \\
\hline Total protein Intake $(\mathrm{g} / \text { day })^{\dagger}$ & $63 \pm 30$ & $59 \pm 22$ & $66 \pm 21$ & 3.649 & 0.312 \\
\hline 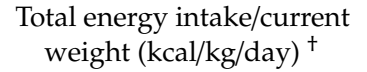 & $23.60 \pm 8.58$ & $24.31 \pm 8.24$ & $26.26 \pm 9.33$ & 1.780 & 0.270 \\
\hline $\begin{array}{l}\text { Total protein intake/ current } \\
\text { weight }(\mathrm{g} / \mathrm{kg} / \text { day })^{+}\end{array}$ & $1.03 \pm 0.43$ & $1.02 \pm 0.38$ & $1.11 \pm 0.36$ & 2.209 & 0.393 \\
\hline $\begin{array}{l}\text { Dietary Energy Intake } \\
{\text { (kcal/day })^{+}}^{+}\end{array}$ & $1355 \pm 62$ & $549 \pm 420$ & $413 \pm 426$ & 57.897 & $<0.0001 *$ \\
\hline $\begin{array}{l}\text { Dietary protein } \\
{\text { Intake }(\mathrm{g} / \text { day })^{+}}^{+}\end{array}$ & $60.5 \pm 31.29$ & $23 \pm 23$ & $16 \pm 21$ & 62.639 & $<0.0001$ * \\
\hline $\begin{array}{l}\text { ONS Energy Intake } \\
(\text { (kcal/day })^{\mathbb{I I}}\end{array}$ & $56 \pm 181$ & $854 \pm 486$ & $1142 \pm 572$ & 75.717 & $<0.0001 *$ \\
\hline ONS Protein Intake (g/day) ${ }^{\mathbb{I}}$ & $2 \pm 8$ & $35 \pm 19$ & $49.99 \pm 24.42$ & 77.568 & $<0.0001 *$ \\
\hline
\end{tabular}

Mean, standard deviation (SD); ${ }^{*}$ Significant $(p<0.05)^{\dagger}$ Analyzed by General Linear Model repeated measures. A Greenhouse-Geisser correction for degrees of freedom was used because of deviation from sphericity; ${ }^{\text {II }}$ Analyzed by the Friedman test; ${ }^{a}$ Wilcoxon signed rank sum test (baseline vs. end of RT). Abbreviations: PG-SGA: patient-generated subjective global assessment, BMI: body mass index, NIS: nutrition impact symptoms, ONS: oral nutrition supplements.

\subsubsection{NIS}

About $80 \%$ HNC patients had NIS before the start of treatment, with only $20 \%$ of patients experiencing no NIS (Table 2). At the end of treatment, all subjects experienced NIS (Table 2). The mean symptoms score increased from $21.78 \pm 4.59$ to $39.68 \pm 9.54$ at the middle of treatment and up to $48.34 \pm 8.79$ at the end of treatment (Table 3). At the baseline, $52 \%$ of HNC patients had the symptom of difficulty chewing (52\%). At the middle of treatment, all HNC patients experienced almost all NIS, except diarrhea, depression, and vomiting. All $50 \mathrm{HNC}$ patients experienced taste changes and a dry mouth at the end of treatment. More than $80 \%$ of them experienced difficulty swallowing, difficulty chewing, a loss of appetite, pain, lack of energy, and a sore mouth (Table 4). 
Table 4. Prevalence of NIS from the HNSC(C) in participants with severity scores $\geq 2$ for orally fed head and neck cancer patients over time.

\begin{tabular}{cccc}
\hline $\begin{array}{c}\text { Nutrition Impact } \\
\text { Symptoms }(\boldsymbol{n}=\mathbf{5 0 )}\end{array}$ & $\begin{array}{c}\text { Baseline } \\
\boldsymbol{n} \mathbf{( \% )}\end{array}$ & $\begin{array}{c}\text { Middle of } \\
\text { treatment } \\
\boldsymbol{n} \mathbf{( \% )}\end{array}$ & $\begin{array}{c}\text { End of treatment } \\
\boldsymbol{n} \mathbf{( \% )}\end{array}$ \\
\hline Taste changes & $5(10)$ & $46(92)$ & $50(100)$ \\
Difficulty swallowing & $9(18)$ & $42(84)$ & $47(94)$ \\
Difficulty chewing & $26(52)$ & $43(86)$ & $47(94)$ \\
Constipation & $8(16)$ & $28(56)$ & $29(58)$ \\
Loss of appetite & $19(38)$ & $46(92)$ & $47(94)$ \\
Dry mouth & $19(38)$ & $46(92)$ & $50(100)$ \\
Pain & $11(22)$ & $38(76)$ & $45(90)$ \\
Anxious & $9(18)$ & $20(40)$ & $22(44)$ \\
Nausea & $4(8)$ & $26(52)$ & $22(44)$ \\
Lack of Energy & $14(28)$ & $40(80)$ & $46(92)$ \\
Sore mouth & $6(12)$ & $34(68)$ & $43(86)$ \\
Diarrhea & $0(0)$ & $3(6)$ & $4(8)$ \\
Thick saliva & $12(24)$ & $44(88)$ & $48(96)$ \\
Depressed & $2(4)$ & $9(18)$ & $10(20)$ \\
Fullness & $4(8)$ & $21(42)$ & $26(52)$ \\
Vomiting & $3(6)$ & $9(18)$ & $11(22)$ \\
Smell bothersome & $6(12)$ & $32(64)$ & $36(72)$ \\
\hline
\end{tabular}

Abbreviations: HNSC@ , Head and Neck Symptoms Checklist.

\subsubsection{Dietary and ONS Intake}

At the end of treatment, normal and soft diet reduced to $42 \%$ while liquid diet increased to $46 \%$ and tube feeding increased to $12 \%$ (Table 2). The total energy and protein intake of HNC patients at baseline was $1412 \pm 589 \mathrm{kcal} /$ day and $63 \pm 30 \mathrm{~g} /$ day respectively. Both results had increased to $1554 \pm$ $482 \mathrm{kcal} /$ day and $66 \pm 21 \mathrm{~g} /$ day at the end of treatment (Table 3).

As shown in Table 3, total energy and total protein did not change significantly over time. However, there were significant changes for dietary energy, dietary protein, ONS energy and ONS protein over time. Dietary energy intake and protein intake decreased significantly throughout the treatment while ONS energy and protein intake increased significantly throughout the treatment. All HNC subjects required ONS during RT treatment. The provision of energy and protein from ONS was $1142 \pm 572$ $\mathrm{kcal} /$ day and $49.99 \pm 24.42 \mathrm{~g} /$ day at the end of treatment (Table 3). This means that more than $70 \%$ of the total energy and protein intake was from ONS among HNC patients at the end of treatment.

\subsubsection{Handgrip Strength}

There was a decreasing trend of non-dominant handgrip strength from $25.17 \pm 7.46 \mathrm{~kg}$ at the beginning, $25.06 \pm 8.26 \mathrm{~kg}$ in the middle, to $24.45 \pm 7.97 \mathrm{~kg}$ at end of treatment (Table 3). Handgrip strength did not significantly change over time $(p=0.483)$ (Table 3$)$.

\subsubsection{ONS Compliance}

There were 37 patients ( $74 \%$ ) who consumed sufficient ( $\geq 75 \%$ of their requirements) ONS energy and protein and were considered to be "compliant". Consumption did not meet the criteria of $\geq 75 \%$ of the recommended ONS energy and protein intake in $26 \%(n=13)$ of patients, who were therefore considered to be "non-compliant" (Table 2). There was a significant difference in the percentage of end treatment weight loss between the ONS compliant group $(6.55 \pm 3.65 \%)$ versus the non-compliant group $(9.75 \pm 4.4 \%)$, with a t-value of -2.570 , where $p=0.013$. (Table 5). The total energy and total protein intakes for the ONS compliant group and ONS non-compliant group were $1653 \pm 461 \mathrm{kcal} / \mathrm{day}$ and $71 \pm 19 \mathrm{~g} /$ day, and $1273 \pm 439 \mathrm{kcal} /$ day and $51 \pm 18 \mathrm{~g} /$ day, respectively. Significant differences of total energy and total protein were found in the intake between the ONS compliant group and the 
ONS non-compliant group $(p<0.05)$ (Table 5). The ONS non-compliant group experienced significant higher muscle mass loss $(2.78 \pm 2.61 \mathrm{~kg})$ compared to the compliant group (Table 5).

Table 5. Weight, muscle, and fat loss, total energy and protein intake, and NIS score according to the ONS compliant group.

\begin{tabular}{|c|c|c|c|c|}
\hline Mean $\pm S D$ & $\begin{array}{l}\text { ONS Compliant } \\
\text { Group }(n=37)\end{array}$ & $\begin{array}{l}\text { ONS Non-compliant } \\
\text { Group }(n=13)\end{array}$ & $t$-Value & $p$-Value \\
\hline Weight loss (\%) & $6.55 \pm 3.65$ & $9.75 \pm 4.4$ & -2.570 & 0.013 * \\
\hline Muscle mass loss (kg) & $1.34 \pm 1.89$ & $2.78 \pm 2.61$ & 2.12 & $0.039 *$ \\
\hline Fat mass loss (kg) & $2.29 \pm 1.73$ & $3.34 \pm 2.22$ & 1.74 & 0.088 \\
\hline Total Energy intake (kcal/day) & $1653 \pm 462$ & $1273 \pm 439$ & 2.579 & $0.013 *$ \\
\hline Total Protein Intake (g/day) & $71 \pm 19$ & $51 \pm 19$ & 3.24 & $0.002 *$ \\
\hline Energy intake (kcal/kg/day) & $28 \pm 9$ & $22 \pm 9$ & 0.079 & 0.079 \\
\hline Total Protein Intake (g/kg/day) & $1.2 \pm 0.3$ & $0.9 \pm 0.4$ & 0.006 & $0.006 *$ \\
\hline NIS score & $47.32 \pm 9.1$ & $51.23 \pm 7.23$ & 1.391 & 0.171 \\
\hline
\end{tabular}

Independent $\mathrm{T}$ test. ${ }^{*} p<0.05$ shows a significant difference between the ONS compliant vs. ONS non-compliant groups. Abbreviations: ONS: oral nutrition supplements, NIS: nutrition impact symptoms.

\subsection{Correlations between Weight Loss and Others Nutrition Parameters}

The PG-SGA score at the end of treatment had a significantly strong positive relationship with weight loss $(r=0.6, p<0.001)$ (Table 6$)$. There was a significant positive relationship between the percentage of weight loss at the end of treatment with the total symptoms score $(r=0.363, p=0.01)$ (Table 6). The higher total symptoms score among HNC subjects, the higher percentage of weight loss at the end of treatment.

Table 6. Correlation between weight loss percentage and the independent variables $(n=50)$.

\begin{tabular}{|c|c|c|}
\hline Independent Variables & Relationship (r) & Significance (p) \\
\hline PG-SGA score ${ }^{b}$ & 0.600 & $0.0001^{* * *}$ \\
\hline NIS score ${ }^{a}$ & 0.363 & $0.01 *$ \\
\hline Total Energy intake $(\mathrm{kcal} / \mathrm{d})^{a}$ & -0.163 & 0.257 \\
\hline Total Protein intake $(\mathrm{g} / \mathrm{d})^{a}$ & -0.199 & 0.167 \\
\hline Diet Energy intake $(\mathrm{kcal} / \mathrm{d})^{a}$ & -0.114 & 0.432 \\
\hline Diet Protein intake $(\mathrm{g} / \mathrm{d})^{a}$ & -0.127 & 0.379 \\
\hline ONS Energy intake $(\mathrm{kcal} / \mathrm{d}) \mathrm{b}$ & -0.049 & 0.736 \\
\hline ONS Protein intake $(\mathrm{g} / \mathrm{d})^{b}$ & -0.034 & 0.814 \\
\hline
\end{tabular}

a Pearson's rho test. ${ }^{\mathrm{b}}$ Spearman's rho test. ${ }^{*} p<0.05$; ${ }^{* * *} p<0.001$ shows significance. Abbreviations: PG-SGA: patient-generated subjective global assessment, NIS: nutrition impact symptoms, ONS: oral nutrition supplements.

\subsection{Correlation Between Total NIS Score and ONS Energy and Protein Intake}

There was a significant positive relationship between the total nutrition impact symptoms score and ONS energy intake at the middle of RT $(r=0.429, p=0.002)$ and a significant positive relationship between the total nutrition impact symptoms score and ONS protein intake $(r=0.412, p=0.003)$ at the middle of RT (Table 7). 
Table 7. Correlation between total NIS score and ONS energy and protein intake $(n=50)$.

\begin{tabular}{lll}
\hline & \multicolumn{1}{c}{ Relationship (r) } & \multicolumn{1}{c}{ Significance $(p)$} \\
\hline ONS energy intake & 0.170 & 0.239 \\
Baseline & 0.429 & $0.002 *$ \\
Middle of RT & 0.106 & 0.466 \\
End of RT & 0.159 & 0.269 \\
ONS protein intake & 0.412 & $0.003 *$ \\
Baseline & 0.124 & 0.389 \\
Middle of RT & End of RT &
\end{tabular}

* Significant with $p<0.05$ Spearmen's rho. Abbreviations: ONS: oral nutrition supplements.

\section{Discussion}

All HNC patients were malnourished at the end of treatment according to PG-SGA in this study (Table 2). Capuano's study showed a strong correlation between involuntary weight loss and PG-SGA, which was similar to our study, where a high PG-SGA score had a strong positive relationship with a high percentage of weight loss at the end of treatment [23]. There was a high prevalence of critical weight loss ( $>5 \%$ ) among HNC at the end of treatment $(68 \%)$ and $30 \%$ of them had weight loss greater than $10 \%$. Patients with critical weight loss during RT had worse disease-specific survival related to poor response to treatment. There was an impaired immune response as a consequence of insufficient food intake in malnourished patients $[10,21]$. Weight monitoring is very important during RT as this treatment requires head masks for precise patient positioning to ensure accurate radiation delivery to target area. Any weight loss during RT will lead to inaccurate radiation delivery to the target area, which can reduce the effectiveness of treatment (i.e., treatment interruption) [24]. Weight maintenance leads to beneficial outcomes and is an appropriate aim for nutritional interventions.

The average daily energy and protein intake in this study was below the ESPEN recommended guideline before treatment [14]. Even though the average daily energy and protein intake were improved at the end of treatment compared to the baseline (Table 3), the intake was still below the recommendation of $30 \mathrm{kcal} / \mathrm{kg} /$ day and $1.2 \mathrm{~g} / \mathrm{kg} /$ day, respectively [14]. This was clearly insufficient because the majority of patients continued to lose weight throughout the treatment because of inadequate energy and protein intake. According to the Prevost review study, optimal nutrition status before treatment is able to improve the effectiveness of treatment and improve treatment outcomes [25]. Malnutrition before treatment will increase the risk of infection [8] and further decrease the survival rate of patients [10]. In this study, $72 \%$ patients had a pre-treatment weight loss problem, where $12 \%$ had critical weight loss $(<5 \%)$, which indicates the importance to start nutrition intervention before treatment (Table 2).

The results of our study show a higher intake of calories and protein at the time that treatment was completed, as compared to the baseline intake. This result is comparable with those of another study [26]. This can be related with more than half of the HNC patients, who had malnutrition at the baseline of treatment due to inadequate food and nutrition knowledge. Some studies have revealed that most cancer patients, having dietary perceptions and beliefs with specific foods restrictions, result in potential malnutrition after diagnoses [27-29].

At the baseline, half of the HNC patients had the symptom of difficulty chewing, which relates to dental extraction one month prior to RT or a tumor located around the oral cavity, affecting the opening of the mouth or post-operation effects on jaw movement [8]. Neoadjuvant chemotherapy prior to RT is one of the reasons HNC patients experienced loss of appetite, dry mouth, lack of energy, thick saliva, and pain. For a patient who is having nutrition impact symptoms prior to RT, ONS initiation should be implemented as soon as beginning of the RT. If possible, HNSC@ is recommended for use during neoadjuvant chemotherapy or as soon as the diagnosis is confirmed, as it is a useful tool to predict dietary intake. 
Our study reported that all HNC patients experienced multiple NIS at the end of treatment, resulting in a high NIS score (Table 4), which was a similar observation from a study Kubrak et al. (2013) [13]. Multiple NIS are more likely to reduce dietary intake, induce weight loss, and decrease the chance of survival. Post-dental extraction prior to treatment might lead to difficulty in chewing hard solid foods prior to treatment. This may worsen during treatment due to the complication of other NIS that further compromise dietary intake. A few research studies of HNC patients have reported a significant association between NIS and reduced dietary intake, weight loss, and reduced functional performance [13-15]. Almost 50\% of our subjects chose liquid diet rather than normal texture diets due to worsening NIS in the middle of treatment and highest at the end of treatment. Foods that are cold, moist, soft, and with sauces, broths or accompanying meals with liquids are better choices for dry mouth patients.

There was an association between weight loss and NIS score (Table 6). The higher NIS score was due to RT resulting in discomfort and difficulty with eating. Most of the patients burdened by NIS prefer to choose ONS as a meal replacement vector. Most ONS were liquids, which may be less satiating and easier to consume than solids when individuals are suffering from pain, loss of appetite or poor dentition [30]. Some patients who suffered from oral mucositis and nausea with bothersome smell problems were able to fulfill compliance well via ONS rather than foods [26]. A greater percentage of energy was derived from liquids which related to a higher NIS burden experienced during treatment. The same result was reported by Nejatinamini study [26]. About $70 \%$ of patients in this study selected ONS as a major contributor to energy intake at the end of treatment. Liquid milk has less triggers for nausea sensation and no chewing effort is required, which reduces the consumption time when compared to solid foods. ONS also contains complete balance nutrients of a sufficient amount to achieve energy and protein requirements, which encourages patients' easy compliance to ONS rather than foods, with neither different types of texture modification nor portion size tolerance modification.

Our study revealed that the ONS non-compliant group experienced significantly higher percentage weight loss, muscle mass loss, lower total energy and protein intake compared to the compliant group (Table 5). Hopanci et al. showed a similar result in their HNC non-compliant group [14]. The ONS non-compliant group was unable to achieve the minimum energy intake of $25 \mathrm{kcal} / \mathrm{kg} /$ day and protein intake of $1 \mathrm{~g} / \mathrm{kg} /$ day. This group lost almost $10 \%$ weight, which has greater risk of death according to a cohort study by Langius et al. (2013) [10]. The energy density, volume, and flavor of ONS supplied may affect the compliance rate [31]. A study from McCurdy et al. (2019) suggested intakes greater than $30 \mathrm{kcal} / \mathrm{kg}$ BW/day may be required to prevent weight loss as well as muscle mass loss [32]. The ONS compliant group was able to achieve the recommended protein intake $(1.2 \mathrm{~g} / \mathrm{kg} /$ day $)$ and experience less muscle mass loss compared to the non-compliant group.

In this study, the ONS compliant group had $>5 \%$ critical weight loss despite dietary counselling and ONS support. The average ONS compliant group achieved $28 \pm 9 \mathrm{kcal} / \mathrm{kg}$, which was below $30 \mathrm{kcal} / \mathrm{kg} /$ day when compared with the current recommendations. The standard compliance rate in this study, according to Hopanci's study, was set at $\geq 75 \%$ as a benchmark for compliance [12]. However, the ONS compliant group in this study still experienced critical weight loss which means that $75 \%$ could not reach the standard compliance rate for HNC patients undergoing RT. Perhaps a suggestion of a $100 \%$ compliance rate can be considered as compliance for better nutrition outcome monitoring. Therefore, the role of a dietitian in counselling with the support of ONS and the process along the treatment are very important to increase patients' compliance towards nutrition intervention in order to effectively optimize nutrition status.

This study has shown that body weight, muscle mass, fat mass, dietary energy and protein intake followed a decreasing trend along the treatment, while the PG-SGA score, NIS score, and ONS energy and protein intake followed an increasing trend (Table 3). Patients in the current study were unable to maintain their lean mass during head and neck cancer treatment. Instead, a significantly higher muscle mass loss was seen among HNC patients in the non-compliant group. The decrease of muscle 
mass in the patients with head and neck cancer in the middle of RT and at the end of RT may reveal the time points where nutritional care should to be provided to patients [24].

In the middle of RT, ONS energy and protein intake contributed to more than half of the energy and protein intake with the majority of patients experiencing a high score of NIS that interrupted dietary intake. The NIS score and ONS intake show a significant positive relationship at the middle of the RT. A higher NIS score requires higher ONS intake, as HNC patients suffer from multiple NIS, including a loss of appetite, dry mouth, taste changes, a sore mouth, difficulty swallowing, difficulty chewing, thick saliva and pain that interrupt eating. ONS should be initiated before the middle of RT due to the increasing NIS score that interrupts eating. Capuano et al. (2008) reported that HNC patients develop severe mucositis and dysphagia within 15 days from the start of treatment [23].

All HNC patients required ONS during RT in this study. An intensive dietary intervention is recommended before problems arise rather than anticipating decreased intake and lost weight. NIS score will be great tool to identify high-risk patients (i.e., those having severe mucositis and dysphagia) who are most likely benefit from early and aggressive intervention and tube placement. Weight loss $\geq 5 \%$ should be part of the criteria for tube initiation when a low ONS compliance rate is observed among HNC patients. The ESPEN guideline recommends tube feeding in RT-induced severe mucositis or in obstructive tumors resulting in dysphagia, anticipating inadequate energy intake [14]. According to the systemic review, the provision of enteral nutrition support via a tube inserted is suggested once oral intake declines below $50 \%$ from the energy requirements or once $>5 \mathrm{~kg}$ of weight loss has occurred from the baseline [33].

This study has several strengths, which include the use of the validated scored PG-SGA and HNSC $^{\odot}$ questionnaires. The scored PG-SGA is a valid tool for nutritional assessment in cancer patients. The HNSC ${ }^{\circledR}$ questionnaire has been validated for assessing NIS in HNC. The longitudinal design of this study makes it possible to assess nutritional changes, dietary changes, and the NIS of HNC patients throughout treatment. This is the first study to assess energy and protein intake from ONS aside from dietary energy and protein intake. It is crucial to identify ONS intake in order to provide sufficient energy and protein intake to reduce weight loss. Further studies of effective nutrition intervention programs could be planned earlier in order to identify early symptoms, prevent drastic weight loss and improve treatment outcome. This may highlight the necessity of the continuous screening of nutrition status, dietary changes and NIS to improve nutrition intervention, such as the timely initiation of oral nutritional supplements or enteral tube feeding.

The relatively small sample size may not have been large enough to allow for the generalizability of the results among all HNC patients. Still, this present study has generated preliminary evidence on the current NIS and nutritional and functional statuses of HNC patients serving as a basis for future research. Weight and BMI are not good parameters to evaluate nutrition status due to every HNC patient having unknown cumulative losses during RT. Hence, further studies for nutrition intervention should include NIS monitoring, PG-SGA, dietary intake apart from weight and BMI, and monitoring during treatment. The findings of this study could add to the existing literature on weight changes in HNC during RT, which can help to optimize nutrition intervention.

\section{Conclusions}

In our study, HNC inpatients in the NCI were observed, from the beginning of RT until the end of treatment. The suggested intensive nutritional care time point was the middle of RT, related with a high NIS score, low dietary intake and high ONS intake. This is the first research study that has monitored NIS using the HNSC(C) checklist to analyze NIS throughout the treatment, and there are several findings that are useful as a contribution for nutrition intervention for HNC patients. ONS compliance affects the percentage of weight loss, muscle mass loss, and total energy and protein intake among HNC patients during RT. As a conclusion, diet monitoring and close advisory has to be conducted for HNC patients in order to ensure better nutrition outcomes during treatment. Further observational studies 
can be conducted with the NIS checklist to achieve a higher accuracy of ONS compliance for the good of HNC patients' dietary needs.

Author Contributions: Conceptualization, methodology, investigation, resources, data curation, formal analysis, visualization and writing original drafts, M.K.N., validation, M.K.N. and Z.A.Z.; supervision, Z.A.Z., Z.A.M.D., N.B.M.Y. and Z.I.; writing—review and editing, Z.A.Z., Z.A.M.D., N.B.M.Y., Z.I., N.J., and Z.A.R.; project administration, M.K.N., Z.A.R. and N.J. All authors have read and agreed to the published version of the manuscript.

Funding: This research received no external funding.

Acknowledgments: The authors would like to would like to express their sincere appreciation to the General Director of the Ministry of Health, Malaysia, for approval of this study as well as the Department of Administration, National Cancer Institute, Putrajaya, for assistance in this study. Besides, we thank the patients who participated and contributed in this study.

Conflicts of Interest: The authors declare no conflict of interest.

\section{References}

1. Boyle, P.; Levin, B. World Cancer Report 2008; IARC Press, International Agency for Research on Cancer: Lyon, France, 2008.

2. Mulasi, U.; Vock, D.M.; Kuchnia, A.J.; Jha, G.; Fujioka, N.; Rudrapatna, V.; Patel, M.R.; Teigen, L.; Earthman, C.P. Malnutrition Identified by the Academy of Nutrition and Dietetics and American Society for Parenteral and Enteral Nutrition Consensus Criteria and Other Bedside Tools Is Highly Prevalent in a Sample of Individuals Undergoing Treatment for Head and Neck Cancer. J. Parenter. Enter. Nutr. 2016, 42, 139-147. [CrossRef]

3. Arribas, L.; Hurtós, L.; Milà, R.; Fort, E.; Peiró, I. Predict factors associated with malnutrition from patient generated subjective global assessment (PG-SGA) in head and neck cancer patients. Nutr. Hosp. 2013, 28, $155-163$.

4. Langius, J.A.E.; Doornaert, P.; Spreeuwenberg, M.D.; Langendijk, J.A.; Leemans, C.R.; Van Der Schueren, M.A.E. Radiotherapy on the neck nodes predicts severe weight loss in patients with early stage laryngeal cancer. Radiother. Oncol. 2010. [CrossRef] [PubMed]

5. Couch, M.; Lai, V.; Cannon, T.; Guttridge, D.; Zanation, A.; George, J.; Hayes, N.; Zeisel, S.; Shores, C. Cancer cachexia syndrome in head and neck cancer patients: Part I.Diagnosis, impact on quality of life and survival, and treatment. Head Neck 2007, 29, 401-411. [CrossRef] [PubMed]

6. Nguyen, T.V.; Yueh, B. Weight loss predicts mortality after recurrent oral cavity and oropharyngeal carcinomas. Cancer 2002, 95, 553-562. [CrossRef]

7. Ravasco, P.; Monteiro-Grillo, I.; Marques Vidal, P.; Camilo, M.E. Impact of nutrition on outcome: A prospective randomized controlled trial in patients with head and neck cancer undergoing radiotherapy. Head Neck 2005, 27, 659-668. [CrossRef]

8. Farhangfar, A.; Makarewicz, M.; Ghosh, S.; Jha, N.; Scrimger, R.; Gramlich, L.; Baracos, V. Nutrition impact symptoms in a population cohort of head and neck cancer patients: Multivariate regression analysis of symptoms on oral intake, weight loss and survival. Oral Oncol. 2014. [CrossRef]

9. Argiris, A.; Li, Y.; Forastiere, A. Prognostic factors and long-term survivorship in patients with recurrent or metastatic carcinoma of the head and neck. Cancer 2004, 101, 2222-2229. [CrossRef] [PubMed]

10. Langius, J.A.E.; Bakker, S.; Rietveld, D.H.F.; Kruizenga, H.M.; Langendijk, J.A.; Weijs, P.J.M.; Leemans, C.R. Critical weight loss is a major prognostic indicator for disease-specific survival in patients with head and neck cancer receiving radiotherapy. Br. J. Cancer 2013, 109, 1093. [CrossRef]

11. White, J.V.; Guenter, P.; Jensen, G.; Malone, A.; Schofield, M.; Academy Malnutrition Work Group; ASPEN Malnutrition Task Force; ASPEN Board of Directors. Consensus statement: Academy of Nutrition and Dietetics and American Society for Parenteral and Enteral Nutrition: Characteristics recommended for the identification and documentation of adult malnutrition (undernutrition). JPEN J. Parenter Enter. Nutr. 2012, 36, 275-283. [CrossRef]

12. Hopanci Bicakli, D.; Ozkaya Akagunduz, O.; Meseri Dalak, R.; Esassolak, M.; Uslu, R.; Uyar, M. The Effects of Compliance with Nutritional Counselling on Body Composition Parameters in Head and Neck Cancer Patients under Radiotherapy. J. Nutr. Metab. 2017. [CrossRef] 
13. Kubrak, C.; Olson, K.; Baracos, V.E. The head and neck symptom checklist(C: An instrument to evaluate nutrition impact symptoms effect on energy intake and weight loss. Support. Care Cancer 2013. [CrossRef] [PubMed]

14. Arends, J.; Bachmann, P.; Baracos, V.; Barthelemy, N.; Bertz, H.; Bozzetti, F.; Preiser, J.C. ESPEN guidelines on nutrition in cancer patients. Clin. Nutr. 2017. [CrossRef] [PubMed]

15. Jager-Wittenaar, H.; Dijkstra, P.U.; Vissink, A.; Van Der Laan BF, A.M.; Van Oort, R.P.; Roodenburg, J.L.N. Critical weight loss in head and neck cancer-prevalence and risk factors at diagnosis: An explorative study. Support. Care Cancer 2007. [CrossRef] [PubMed]

16. Bauer, J.; Capra, S.; Ferguson, M. Use of the scored Patient-Generated Subjective Global Assessment (PG-SGA) as a nutrition assessment tool in patients with cancer. Eur, J. Clin. Nutr. 2002, 56, 779-785. [CrossRef] [PubMed]

17. Stewart, B.W.; Wild, C.P. World Cancer Report 2014; World Health Organization: Geneva, Switzerland, 2014; pp. 1-2.

18. Chien, T.P.; Lian, N.G.; Mohd Firdaus, N.S. Medical Nutrition Therapy Guidelines for Cancer in Adults; Ministry of Health Malaysia: Kuala Lumpur, Malaysia, 2012; pp. 1-71.

19. Brown, T.; Ross, L.; Jones, L.; Hughes, B.; Banks, M. Nutrition outcomes following implementation of validated swallowing and nutrition guidelines for patients with head and neck cancer. Support. Care Cancer 2014, 22, 2381-2391. [CrossRef] [PubMed]

20. Schmidt, K.N.; Olson, K.; Kubrak, C.; Parliament, M.; Ghosh, S. Validation of the head and neck patient symptom checklist as a nutrition impact symptom assessment tool for head and neck cancer patients. Support. Care Cancer 2013. [CrossRef] [PubMed]

21. Van der Laan, H.P.; Bijl, H.P.; Steenbakkers, R.J.; van der Schaaf, A.; Chouvalova, O.; Vemer-van den Hoek, J.G.; Gawryszuk, A.; van der Laan, B.F.A.M.; Oosting, S.F.; Roodenburg, J.L.N.; et al. Acute symptoms during the course of head and neck radiotherapy or chemoradiation are strong predictors of late dysphagia. Radiother. Oncol. 2015, 115, 56-62. [CrossRef]

22. Lemeshow, S.; Hosmer, D.W.; Klar, J.; Lwanga, S.K.; World Health Organization. Adequacy of Sample Size in Health Studies; Wiley: Chichester, UK, 1990. [CrossRef]

23. Capuano, G.; Grosso, A.; Gentile, P.C.; Battista, M.; Bianciardi, F.; Di Palma, A.; Pavese, I.; Satta, F.; Tosti, M.; Palladino, A.; et al. Influence of weight loss on outcomes in patients with head and neck cancer undergoing concomitant chemoradiotherapy. Head Neck: J. Sci. Spec. Head Neck 2008, 30, 503-508. [CrossRef]

24. Tang, P.L.; Wang, H.H.; Lin, H.S.; Liu, W.S.; Chen, L.M.; Chou, F.H. Body Composition Early Identifies Cancer Patients With Radiotherapy at Risk for Malnutrition. J. Pain Symptom Manag. 2018, 55, 864-871. [CrossRef]

25. Prevost, V.; Joubert, C.; Heutte, N.; Babin, E. Assessment of nutritional status and quality of life in patients treated for head and neck cancer. Eur. Ann. Otorhinolaryngol. Head Neck Dis. 2014, 131, 113-120. [CrossRef]

26. Nejatinamini, S.; Kubrak, C.; Álvarez-Camacho, M.; Baracos, V.E.; Ghosh, S.; Wismer, W.V.; Mazurak, V.C. Head and neck cancer patients do not meet recommended intakes of micronutrients without consuming fortified products. Nutr. Cancer 2018, 70, 474-482. [CrossRef] [PubMed]

27. Totadri, S.; Radhakrishnan, V.; Atreya, H.; Shenoy, P.K.; Ganesan, P.; Ganesan, T.S.; Sagar, T.G. Dietary perceptions and beliefs among families with children undergoing therapy for cancer. Pediatr. Hematol. Oncol. J. 2017, 2, 25-28. [CrossRef]

28. Beeken, R.J.; Williams, K.; Wardle, J.; Croker, H. “What about diet?” A qualitative study of cancer survivors' views on diet and cancer and their sources of information. Eur. J. Cancer Care 2016, 25, 774-783. [CrossRef] [PubMed]

29. Farooqui, M.; Hassali, M.A.; Shatar, A.K.; Shafie, A.A.; Seang, T.B.; Farooqui, M.A. A qualitative exploration of Malaysian cancer patients' perspectives on cancer and its treatment. BMC Public Health 2011, 11, 525. [CrossRef]

30. Lønbro, S.; Petersen, G.B.; Andersen, J.R.; Johansen, J. Prediction of critical weight loss during radiation treatment in head and neck cancer patients is dependent on BMI. Support. Care Cancer 2016, 24, 2101-2109. [CrossRef]

31. Hubbard, G.P.; Elia, M.; Holdoway, A.; Stratton, R.J. A systematic review of compliance to oral nutritional supplements. Clin. Nutr. 2012. [CrossRef] [PubMed] 
32. McCurdy, B.; Nejatinamini, S.; Debenham, B.J.; Álvarez-Camacho, M.; Kubrak, C.; Wismer, W.V.; Mazurak, V.C. Meeting Minimum ESPEN Energy Recommendations Is Not Enough to Maintain Muscle Mass in Head and Neck Cancer Patients. Nutrients 2019, 11, 2743. [CrossRef] [PubMed]

33. Bishop, S.; Reed, W.M. The provision of enteral nutritional support during definitive chemoradiotherapy in head and neck cancer patients. J. Med. Radiat. Sci. 2015, 62, 267-276. [CrossRef]

(C) 2020 by the authors. Licensee MDPI, Basel, Switzerland. This article is an open access article distributed under the terms and conditions of the Creative Commons Attribution (CC BY) license (http://creativecommons.org/licenses/by/4.0/). 